\title{
Orion European Service Module (ESM) development, integration and qualification status
}

\author{
Philippe Berthe ${ }^{1}$ \\ European Space Agency, Noordwijk, 2200 AZ, The Netherlands \\ Ann P. Over ${ }^{2}$ \\ NASA Glenn Research Center, Cleveland, OH, 44135 \\ Michelle Picardo ${ }^{3}$ \\ Airbus Defence \& Space, Bremen, 28199, Germany \\ and \\ Anthony W. Byers ${ }^{4}$ \\ Lockheed Martin Space Systems, Littleton, CO, 80127
}

\begin{abstract}
ESA and the European Industry are supplying the European Service Module for Orion. An overview of the system and subsystem configuration of the Orion European Service Module (ESM) as designed and built for the EM-1 mission is provided as well as an outline of its development, assembly, integration and verification process performed by ESA and NASA in coordination with their respective Industrial prime contractors, Airbus Defence and Space and Lockheed Martin.
\end{abstract}

\section{Introduction}

COLLOWING the very successful series of five Automated Transfer Vehicle (ATV) missions to the International F Space Station (ISS) which were completed in 2015, ESA and NASA jointly decided to partially offset the European obligations deriving from the extension of the ISS Programme until the end of 2020 with different means. The selected barter option was a new development : the provision by ESA of the European Service Module (ESM) for NASA's new Orion human exploration spacecraft as part of the Exploration Mission 1 (EM-1). This development and production was entrusted to the prime contractor of the ATV, Airbus Defence and Space in Bremen, Germany.

After feasibility studies from 2011 to 2012, the 2012 ESA Ministerial Council in Naples, Italy, gave the green light for Europe to provide a first European Service Module of NASA's Orion as an in-kind contribution for ISS operations for 2017-20. This decision was strategically important for Europe, as it enabled cooperation between ESA and NASA on the future space transportation system for human exploration. This cooperation has been further strengthened by the decision taken early 2017 to provide a second European Service Module for the following Orion mission, EM-2.

This paper gives an overview of the system and subsystem configuration of the Orion European Service Module (ESM) as designed and built for the EM-1 mission as well as an outline of its development, assembly, integration

\footnotetext{
${ }^{1}$ Manager ESM Project Management Support, Orion-ESM Development Division, Keplerlaan 1, 2200 AG Noordwijk, Senior Member.

${ }^{2}$ NASA Deputy Manager, European Service Module Integration Office, NASA Glenn Research Center 21000 Brookpark Road Cleveland, OH 44135, and AIAA Lifetime Member.

${ }^{3}$ Orion-ESM Project Operations Manager, Space Systems, Airbus Allee 1, 28195 Bremen.

${ }^{4}$ Orion Production and Operations Sr. Manager, Littleton, CO 80127
} 
and verification process performed by ESA and NASA in coordination with their respective Industrial prime contractors, Airbus Defence and Space and Lockheed Martin.

\section{Orion}

Orion is the NASA spacecraft which will send humans and cargo into space beyond Low Earth Orbit (LEO) and to return them safely to Earth. It is being developed for crewed missions to cislunar space. The vehicle is also planned as a back-up vehicle for missions to the ISS (International Space Station). Orion will be launched by the SLS (Space Launch System).

The first test flight of Orion was successfully completed in December 2014 with a Delta IV launch vehicle that launched the Orion Crew Module into a high elliptical orbit to demonstrate high-speed atmospheric Earth re-entry. This flight test did not include the European Service Module.

EM-1 will fly a mission profile similar to what might be used in a future mission to the vicinity of the Moon. The un-crewed Orion travels to a lunar (Distant Retrograde Orbit (DRO), and then returns on a trajectory ending in a high speed atmospheric entry on the order of $\sim 11 \mathrm{~km} / \mathrm{s}$ to demonstrate the performance and effectiveness of the Orion Thermal Protection System, as well as relevant environments prior to the first crewed launch of the vehicle. The total mission duration is 25 days (6 at destination). This will be the first flight of the ESM.

The Orion architecture configuration consists of the following modules:

- Crew Module (CM)

- European Service Module (ESM)

- Crew Module Adapter (CMA)

- Spacecraft Adapter (SA)

- Spacecraft Adapter Jettisoned Fairings (SAJ)

- Launch Abort System (LAS)

ESA is providing the ESM while all other elements are under the responsibility of NASA. The Service Module (SM) refers to the combined CMA + ESM + SA + SAJ.

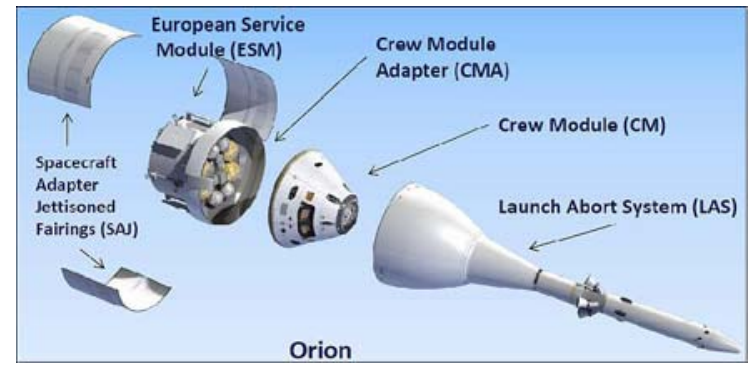

Figure 1. Breakout of the Orion modules

\section{Orion-ESM overall characteristics}

The Orion European Service Module is a cylindrical unpressurized module with a diameter of $4.5 \mathrm{~m}$ and a total length - main engine (Orbital Manoeuvring System Engine - OMS-E) excluded - of $2.7 \mathrm{~m}$. It is fitted with four solar wings with a span of $18.7 \mathrm{~m}$ when deployed. Its dry mass is 3.5 metric tons and it can carry 8.6 tons of propellant.

The external radiators which enclose the body of the ESM form the outer shell of the module. They have two main functions, which are to transfer the module heat loads to the exterior environment, and to constitute the first barrier of the Micrometeoroid/Debris Protection Shield (MDPS). The second barrier made of Nextel and Kevlar blankets is layered against the back side of the radiators. The externally mounted Reaction Control System Pods and Solar Arrays must be designed such that these respect the Orion SAJ geometrical interface.

The top surface of the Orion ESM is defined by the tank platform. The equipment located on the top surface protrudes into the empty internal volume defined by the Crew Module Adapter,

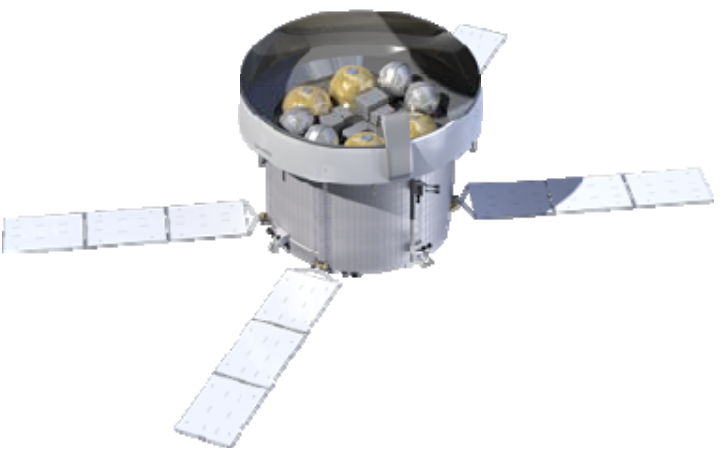

Figure 2. Overall view of the European Service Module (ESM). and the Crew Module heat shield. The equipment of the tank platform consists of the FCA (Fluid Control Assembly); the PCA (Pressure Control Assembly), propellant tank domes, and one helium tank dome of the PSS and the Nitrogen and Oxygen tanks of the CSS (Consumable Storage System). This region will also contain all fluid and electrical connections to the CMA.

The lower surface of the Orion-ESM is covered by an MDPS, which covers the lower equipment bay. Not covered by the MDPS are the main engine (OMS-E) and the Auxiliary Thrusters. The majority of the propulsion isolation equipment, including propellant tubing and valves, the OMS Thrust Vector Control (TVC), and the domes of the propellant tanks are located beneath the MDPS. 
The main functions of the European Service Module are to bring the structural continuity between the launcher and the crew module, to provide critical functions for the crew including propulsion in deep space, thermal control, electrical power, and life support systems including water, oxygen and nitrogen for the mission. The Module is designed for long duration missions high above the Earth and to go beyond the moon.

\section{Orion ESM subsystems}

The ESM consists of the following subsystems.

\section{A. Structure}

The structure of the ESM has two main functions:

- Structural function, which consists in supporting all and transmitting all loads (external and internal). It acts like a launcher stage and interfaces with the Spacecraft Adaptor (SA) on the bottom and the Crew Module Adaptor (CMA) on the top.

- The Micrometeoroid and Orbital Debris (MMOD) protection function, providing protection to all internal systems.

The primary structure of the ESM is made of six longerons of machined aluminum which transfer the loads from the Crew Module Adapter to the lower interface (six SA pyronut separation systems) and of a central core which accommodates most of the subsystem equipment. The

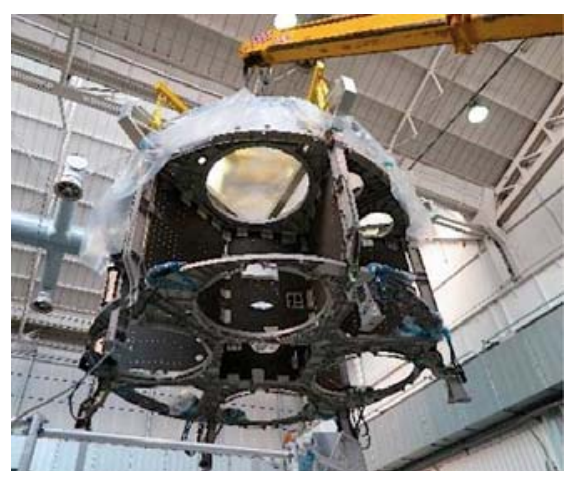

Figure 3. Primary structure of the ESM STA-1, similar to the primary structure of the ESM-1.

six longerons support directly some external equipment such as
Reaction Control System pods, and the four Solar Array Wings.

The central core is itself made of three elements, an assembly made of radial shear webs and internal square webs assembly, a tank bulkhead at the front of the ESM and a lower platform at its bottom.

The web assembly made of carbon sheets and aluminum sandwich, stiffen the central core and accommodate most of the ESM equipment (pressurant tanks, water tanks, forward attachment of solar arrays, electronic components, fluidic components, etc...). The OMS-E is attached to the internal square via a dedicated platform.

The tank bulkhead, made of machined aluminum, supports the four propellant tanks and the CSS tanks for gas (nitrogen and oxygen) delivery, the Fluid Control Assembly (FCA) and provides the main link between the lower interface ring of the CMA and the rest of the ESM structure.

The lower platform, made of machined aluminum as well, supports most of the propulsion equipment, such as the Auxiliary thrusters, and the propulsion isolation equipment, the aft attachment of solar arrays, and the Solar Array Drive Mechanism (SADM).

Below the lower platform is located the aft bumper which is providing MMOD protection to aft area of the ESM.

The secondary structures transmit the loads (loads at launch and in-orbit loads) from the primary structure to the ESM equipment and components, and then support the dynamic inertial loads generated by the same ESM equipment.

The MDPS is a MMOD protection structural element which protects all internal items. This protection function is shared with the Thermal Control System (TCS) whose radiators are accommodated above the MDPS, indeed acting as its first layer. The MDPS is made of metallic and Nextel reinforced MLI elements.

\section{B. Propulsion}

The propulsion system is a bi-propellant system using mixed oxides of nitrogen (MON) and Mono-methyl hydrazine (MMH). The propulsion provides impulse for lunar orbit injection and return to Earth as well as attitude control for the crew module. It is based on a main engine which is the Orbital Maneuvering System-Engine (OMSE) of the Space Shuttle Orbiter, a set of eight auxiliary thrusters which provide low thrust for orbital manoeuvres, as well as redundancy for the main engine, and 24 Reaction Control System (RCS) thrusters for attitude control actuation. The propulsion system can also be used, during some late phases of the launch, for crew safeguard during potential abort scenarios.

The single OMS-E engine is coming from the NASA inventory from the Space Shuttle programme $(27.7 \mathrm{kN})$. It is delivered by NASA as a Government Furnished Equipment (GFE) and will be used during ascent abort and transearth injection manoeuvres as well as orbit change manoeuvres. This engine is gimbaled with an amplitude of $\pm 7^{\circ}$ 


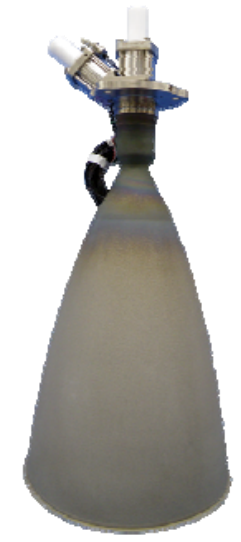

Figure 4. Aerojet engine, similar to the ESM auxiliary thrusters. around both axes (pitch and yaw). The actuation is performed by its Thrust Vector Control (TVC), also of Shuttle program origin.

The 8 Aerojet R4D-11 auxiliary thrusters are closely related to those used on the ATV (490 N) and are used during ascent abort and separation from the SLS together with the main engine. They are also used as back-up to the main engine for TransEarth Injection (TEI) and for trajectory correction manoeuvres.

The 24 RCS thrusters which are the same as used on ATV (220 N) provide the impulse necessary for translation and attitude control manoeuvres. These thrusters are accommodated into six RCS pods. Two pods are composed of four roll thrusters, placed along the ESM lateral surface under the CMA, while four other pods are composed of four thrusters, placed along the ESM lateral surface under the level of the first four pods.

Each propellant type is stored in two titanium propellant tanks, both sets of propellant tanks being arranged in a series configuration. Each propellant tank has a volume of $2.1 \mathrm{~m}^{3}$, allowing to carry 8.6 metric tons of propellant. The propellant tanks are pressurized with helium which is stored in two high pressure vessels and regulated by an electronic pressure regulator.

The propellant distribution network provides the connections between the propellant tanks and the isolation valves and then onwards to the thruster assemblies.

Fill and Drain Valves and the related access lines are used during ground testing and for loading and unloading of the propellant and pressurized tanks. They are located in the CMA to enable access even after the SAJ around the service module has been installed.

The pressure in the propellant lines is be regulated by an electronic Pressure Regulation Unit (PRU). Control and Monitoring of the propulsion subsystem is be performed by a Propulsion Drive Electronic (PDE). The PDE is connected via an Orion Data Network (ODN) to the Vehicle Management Computer (VMC) of the Crew Module. The ESM propulsion will be controlled by the Guidance Navigation \& Control (GNC) system of the CM.

\section{Avionics}

The European Service Module avionics manages the powered equipment of the module and the data exchange services based on instructions received from the flight computers of Orion in the Crew Module that are designed and developed by NASA and its contractors.

The ESM equipment is gathered in Functional Chains which are part of the Orion overall functional architecture designed for the accomplishment of its missions.

The main link with Orion Crew Module on-board computers is the Orion Data Network (ODN network), based on a time-triggered Ethernet solution. This interface ensures the connection of all ESM avionics to the on-board computers and allows the ESM to receive commands and to deliver monitors.

A small set of discrete lines ensures the independent command of ESM power subsystem electronics, allows to acquire signals from 8 sun sensors used as back-up and allows the transfer of data acquired from the development flight instrumentation.

Additionally, dedicated pass-through harness is connecting the CMA to the SA/SAJ and launcher to allow transfer of monitors data and command separations.

During its first mission the ESM will also be fitted with Development Flight Instrumentation (DFI). A number of sensors will be placed in the ESM and the data will be collected for later flight data evaluation.

\section{Software}

The Orion-ESM has no computer nor software on its own, except on some decentralized equipment such as the PDE. Therefore during the mission the content and performance of each on-board Functional Chain are implemented within the Orion Flight Software hosted by the VMC of the Crew Module, in charge of :

- the configuring of the Functional Chain to establish the functions needed in the current phase of the mission, or to recover from the occurrence of failures;

$$
4
$$

American Institute of Aeronautics and Astronautics 
- the monitoring of the Functional Chain to detect possible failures occurring on ESM equipment.

The part of the Orion Flight Software implementing those functions for the ESM Management is called the ESM Control software.

\section{E. Power}

The function of the Electrical Power System (EPS) is to provide the power for all modules of Orion. The EPS manages the power generated by the four Solar Array Wings (SAW) of the ESM. The Power Control and Distribution Unit (PCDU) provides the power interface between the ESM and the CMA, distributes electrical power to ESM electrical equipment and protects the power lines.

The Power Generation part of the ESM EPS consists of four SAW. Each wing is composed of three deployable composite Carbon Fiber Reinforced Polymer rigid panels covered with triple junction Gallium Arsenide solar cells forming nine sections of solar cells strings. In nominal condition the four SAW can supply a total $11.2 \mathrm{~kW}$. The maximum CMA/CM power demand is $7.3 \mathrm{~kW}$, this figure being applicable even with one wing failed.

A Hold Down and Release Mechanisms (HDRM) supports the arrays during launch phase.

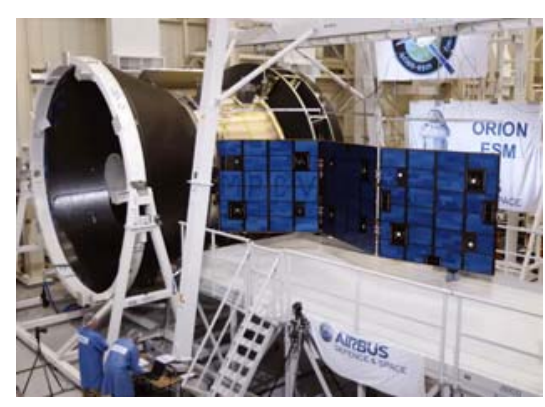

Each SAW is linked to the ESM structure by a two degrees of freedom Solar Array Drive Assembly (SADA). The SADA ensures the power and signal transfer from the SAW to the PCDU. It is composed of a mechanism (SADM) and a Solar Array Drive Electronics (SADE).

The SADM allows Sun-tracking by the SAW in two independent axes. In the Sun-tracking mode the inner axis can swivel between -35 and +25 deg., while the outer axis has a continuous rotation capability [0 to +360 deg.].

The SADM also allows canting of the SAW to reduce the loads on the SAW and SADM during the different Orion orbital maneuvers. During

Figure 6. SAW deploy test Trans-Lunar Injection (TLI) a $0.5 \mathrm{~g}$ acceleration is generated by the Interim Cryogenic Propulsion Stage (ICPS) engine and at Lunar Orbit Insertion (LOI) and Trans-Earth Injection (TEI) a $0.3 \mathrm{~g}$ deceleration is generated by the OMS-E engine. In order to reduce these loads to an acceptable level, the SAWs are repositioned by the SADM. In TLI the SAWs are thus canted during the maneuver to inner axis $=-60 \mathrm{deg}$. $/$ outer axis $=0 \mathrm{deg}$. In LOI/TEI the SAWs are canted to inner axis $=+55 \mathrm{deg}$. $/$ outer axis $=0$ deg.

For monitoring purposes a video camera will be installed at the extremity of each SAW. These four cameras will allow to provide imagery of the spacecraft during the mission.

The EPS distributes the generated power to the CMA through four independent $120 \mathrm{~V}$ buses. The power interface of the PCDU also protects each unregulated bus from overload or short circuit failures on feeder busses outside the PCDU. Additional and independent power lines are provided for the wireless cameras installed on top of SAWs.

\section{F. Thermal Control System}

The thermal control includes an active portion, which transfers the heat of the whole vehicle to the ESM radiators, and a passive portion, which protects the ESM from internal and external thermal environments.

The active portion of the thermal control is designed to collect the thermal loads from the Crew Module and the ESM powered equipment, and to reject thermal loads toward the space radiative sink. Its architecture is based on a Single-phase Fluid Loop Architecture using the HFE-7200 coolant to collect and to transfer the heat loads from both ESM avionics (via cold plates) and CM (via Inter-Loop Heat Exchanger) and to reject them through specific body mounted radiators. The ATCS is composed of two fully independent loops working simultaneously (hot redundancy approach).

The passive portion provides the thermal control of ESM hardware (propulsion, CSS, power and avionic items) and reduces the temperature gradients and minimize heat flows through the internal elements.

It has two main components, heaters (with thermistors and wire heater) and insulation (MLI Thermal Blankets, including some specific High Temperature MLI blankets, for thrusters and engine nozzle thermal impingement protection).

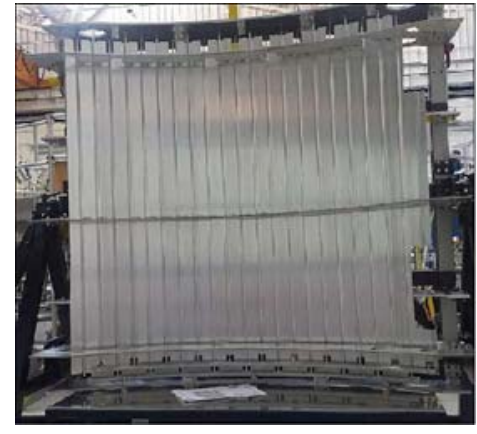

Figure 7. Sample radiator panel. 


\section{G. Consumable Storage System}

The Consumable Storage System (CSS) provides potable water, nitrogen and oxygen to the Crew Module. As an option for some specific missions, the CSS can also provide water to a sublimator located in the CMA via a mission kit composed of a dedicated tank assembly and water distribution system.

Potable water is provided by the Water Delivery System (WDS). The water is stored in four metal bellow tanks, covering usable water needs of the crew for the duration of the mission. The WDS also includes the valves, temperature and quantity sensors as well as the distribution lines towards the interface with the CMA.

Oxygen and nitrogen are provided by the Gas Delivery System and stored in four tanks, the allocation of the tank to each gas being mission dependent. The GDS also includes the pressure regulators, the valves, the temperature and pressure sensors, the hydrophobic filters upstream the water tanks and the distributions lines towards the interface with the CMA and the interface with the Ground Support Equipment (GSE for filling on ground).

\section{H. Unpressurized Cargo}

In the ESM there is a specific compartment for the optional accommodation of Unpressurized Cargo. This compartment will be provided with electrical power and is connected via a harness interface to the CMA.

\section{Orion ESM models}

Some of the models which have been used over the course of the ESM programme are outlined.

\section{A. Structural Test Articles}

Two Structural Test Articles are used for structural verification. It has been decided to produce two modules in order to accommodate the schedule.

- STA-1 has the same weight and configuration as the actual ESM and underwent advanced testing at NASA's Plum Brook Station in Sandusky, Ohio, through the end of 2016. It has been used for the testing and model validation of static, dynamic, acoustic and shock environments of the ESM. The ownership of the STA has been handed over to NASA/Lockheed for integration in the Orion vehicle structural test article and it will be used again in 2017 for additional structural testing at the vehicle level.

- STA-2 has been manufactured together with the primary structure of the ESM-1 flight model for EM-1 and has undergone ultimate testing in 2017 in Thales Alenia Space-Italy (TAS-I) Turin, Italy.

Additionally, in the frame of the structural verification, hypervelocity impact tests have also been performed in the United States on samples of the ESM MDPS.

\section{B. Propulsion Qualification Model}

The Propulsion Qualification Model (PQM) is the test bench designed to

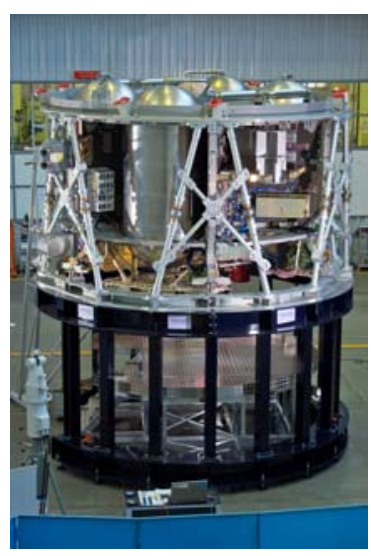

Figure 8. Structural Test Article STA-1.

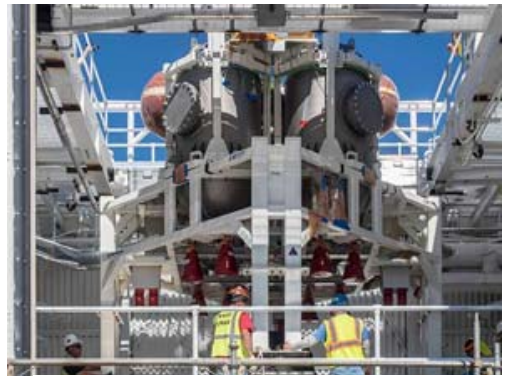

Figure 9. Propulsion Qualification Model (PQM) in White Sands, NM.

support the propulsion subsystem verification. It has been assembled by OHB in Sweden and represents the propulsion system for testing purposes. It was shipped to the United States and starting in July 2017 is undergoing testing in White Sands Test Facility in New Mexico to verify the performance of the multiple types of rocket engines, propellant feed systems, and various other propulsion operations during nominal and off-nominal conditions.

The configuration of the PQM is based on the complete set of orbital manoeuvring engines (OMS-E and Auxiliary thrusters) plus one of the two RCS branches.

The PQM will test the driving firing sequences and thrusters combination to give confidence on the subsystem performance and to support the models correlation. The test configuration is based on the complete set of orbital manoeuvring engines plus one of the two RCS branches.

\section{ESM-QF}

The European Service Module Qualification Facility (ESM-QF) in Airbus Defence and Space, Les Mureaux, France allows the functional verification of the ESM from first ESM test software development needs, up to final ESM electrical system qualification. 
The ESM-QF has been developed in iterations, starting from a mainly numerical configuration up to final one with representative test equipment. The test set-up of the ESM-QF is based on engineering models of the ESM controllers and on the simulation of the various subsystems interfacing them. The CMA/CM interface is simulated by purpose-designed test equipment providing representative behaviours supplied by Lockheed Martin, able to simulate the ODN, discrete and power interfaces. The test facility is under integration in Airbus Defence and Space Les Mureaux.

The ESM-QF will allow to perform the oveall electrical testing related to the Power architecture of the module and verify the ESM software requirements. It will also support the preparation of the AIT procedure for the ESM.

Whenever a better representativity of the interfaces is needed, the corresponding qualification tests will be performed in the United States, at the Integrated Test Laboratory in Denver which is described below.

\section{ESM-ITL}

The ESM-ITL in Lockheed Martin Denver, Colorado is a self-standing facility which serves as a functional representation of the Orion ESM within the overall Orion Integrated Test Laboratory (ITL).

The European functional simulator includes the engineering models of the ESM controllers (equipment connected to the ODN bus : PCDU, PDE, TCU, SADE, PRU), and harness and electric interfaces to the actual equipment.

The components of the simulator were processed in Les Mureaux, France and are used to test the electrical and functional design of the service module, reproducing mission scenarios and verifying that the module will react correctly to any unexpected events that could occur.

After assembly and testing in Les Mureaux at the Airbus Defence and Space site, the functional model was shipped to Denver, USA, where it was connected to the complete Orion ITL. The avionics of the crew module and of the European service module are undergoing testing to ensure the two systems work together as planned, running virtual scenarios to ensure the software performs correctly with all possible conditions.

The test campaign in Denver will run through early 2019.

\section{Current status of the Flight Models}

The current agreement foresees the development and production by Europe of two flight models.

\section{A. Status of ESM-1}

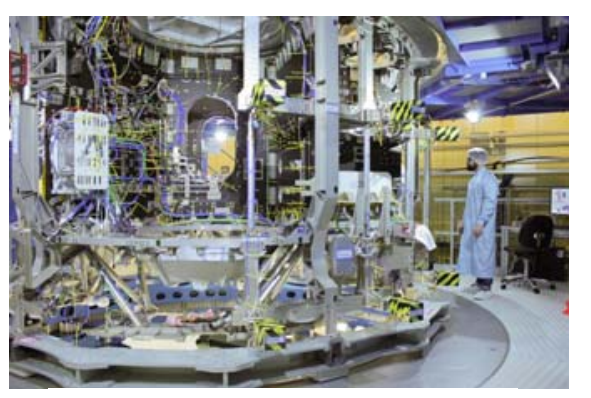

The first ESM module, ESM-1, is in the final stages of assembly in Europe and is planned to be delivered to NASA in 2018. It will be used for the uncrewed flight test of Orion called Exploration Mission-1 (EM1).

The integration of the ESM is ongoing in the Airbus Defence and Space clean-room in Bremen. The primary structure was delivered by TAS-I and currently, the assembly, integration and testing of the various sub-systems and components inside the module is being performed. The AIT integration sequence is driven by the accessibility to different parts of the module as more and more components and

Figure 10. ESM-1 integration in Bremen, Germany equipment are delivered and installed and the space inside the module is constrained.

After harnesses and brackets are installed onto the structure, the heaters and thermistors on structure and components are affixed and tested within
system components have been manufactured and are integrated together with the AIT flow. The first propulsion sub-system components have been manufactured and are integrated together with
the complex propulsion sub-system piping system which will continue as more components including the four propellant tanks are available. The Auxiliary thrusters have been integrated under the ESM lower platform. All welded connections will be x-ray and eddy current inspected as well as proof- and leak-tested.

Various avionics boxes will also be installed and tested in the coming months after which the functional testing for the sub-system assemblies are planned. The Pressure Control Assembly for the propulsion sub-system will be one of the last elements to be integrated and is needed for the PSS functional tests.

The Solar Arrays will be installed in the U.S. after transport of the ESM next year.

\section{B. Status of ESM-2}

American Institute of Aeronautics and Astronautics 
The components of the second flight model, ESM-2, are being produced within the industrial team and its integration in Bremen will start around the turn of the year, once the primary structure of the module has been delivered by TAS-I.

\section{Beyond ESM-1}

NASA, in partnership with the European Space Agency (ESA), is leading the next steps into deep space near the moon, where astronauts will build and begin testing the systems needed for challenging missions to deep space destinations including Mars. The area of space near the moon offers a true deep space environment to gain experience for human missions that push farther into the solar system, access the lunar surface for robotic

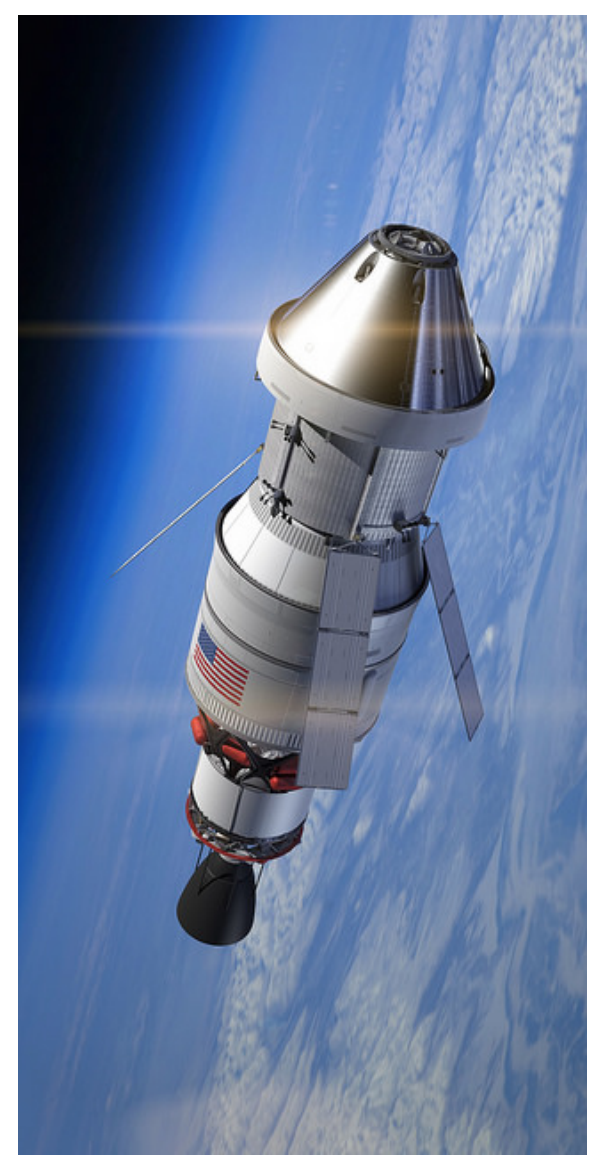
missions lis working on a Deep Space Gateway architecture in the vicinity of the moon.

The period of exploration will begin with Exploration Mission-1, the first integrated mission of the Space Launch System (SLS) rocket and the Orion spacecraft. NASA is working with domestic and international partners to solve the great challenges of deep space exploration. For example, the ESA service module (ESM) is critical since it is Orion's powerhouse that provides essential in-space propulsion, power, air and water for astronauts. Missions in the vicinity of the moon will span multiple phases as part of NASA's framework to build a flexible, reusable and sustainable infrastructure that will last multiple decades and support missions of increasing complexity.

Following initial missions and demonstration of the safe operation of the integrated SLS rocket and Orion spacecraft, NASA is planning a Deep Space Gateway architecture. The architecture is envisioned as a crew tended spaceport in lunar orbit to serve as a gateway to vicinities beyond the moon and the lunar surface. This Deep Space Gateway would have a power bus, a small habitat to extend crew time, docking capability, an airlock, and serviced by logistics modules to enable research. The propulsion system on the gateway mainly uses high power electric propulsion for station keeping and the ability to transfer among a family of orbits in the lunar vicinity. The three primary elements of the gateway, the power and propulsion bus and habitat module, and a small logistics module(s), would take advantage of the cargo capacity of SLS and crewed deep space capability of Orion, including key capabilities of the ESM to allow astronauts to maneuver gateway elements. Building the deep space gateway will allow engineers to develop new skills and test new technologies that have evolved since the assembly of the International

Figure 11. Orion with ICPS (mission EM-1) Space Station.

In this context, the second ESM, ESM-2, will be delivered in 2019 for the first crewed flight of Orion, EM-2, as early as 2021. This will be NASA's first Orion mission with a crew in a series of missions around the Moon. This mission EM-2 will be launched by the SLS together with the $40 \mathrm{~kW}$ Power and Propulsion Bus which will be the first element of the Deep Space Gateway in a Near-Rectilinear Halo Orbit (NRHO) around the Moon. While the Power and Propulsion Bus would place itself in NRHO, Orion will perform a flyby of the Moon on a direct return Multi-Trans Lunar Injection (MTLI) trajectory.

After the ESM-2 the participation of ESA in the following service modules (for EM-3, EM-4...) and their design is currently evaluated by both Agencies and their industrial contractors. The subsequent service modules will support the Orion missions to bring the Gateway components to the orbital facility: Habitat, Logistics and Airlock Modules. To perform these missions, Orion will accomplish orbital transfer and rendezvous maneuvers with the Gateway, all that being accomplished in a composite configuration with a Gateway module. Therefore the service module will have to be adapted for this more demanding propulsive and controllability function. 


\section{Conclusion}

The inclusion of an International Partner in the development and production of Orion is beneficial to both NASA and ESA and constitutes to date the most significant International contribution towards NASA's exploration program. The ESA provided ESMs will be part of the first two flights of Orion beyond Low Earth Orbit, including its first crewed mission, and have allowed the US contractors to focus on the development of the Crew Module and Adapter, Spacecraft Adapter, and Launch Abort System.

In addition, the ESM provided ESA an opportunity for cooperation that leverages skills and knowledge created within the ISS program including for the Automated Transfer Vehicle (ATV). The ESM will also benefit ESA in the development of additional capability for use toward future ESA missions, creation of long term cooperation on future programs such as the Deep Space Gateway and to strengthen the strategic partnership with NASA. The NASA and ESA teams including their respective contractors are now working together and making swift progress towards the shipment of the ESM-1 from Bremen, Germany to NASA Kennedy Space Center and the initial integration of the ESM-2 in Europe.

\section{List of acronyms}

$\begin{array}{ll}\text { ATCS } & =\text { Active Thermal Control System } \\ A T V & =\text { Automated Transfer Vehicle } \\ C F R P & =\text { Carbon Fiber Reinforced Polymer } \\ C M A & =\text { Crew Module Adapter } \\ C S S & =\text { Consumable Storage System } \\ D R O & =\text { Distant Retrograde Orbit } \\ D F I & =\text { Development Flight Instrumentation } \\ E M & =\text { Exploration Mission } \\ E P S & =\text { Electrical Power System } \\ E S A & =\text { European Space Agency } \\ E S M & =\text { European Service Module } \\ E S M-Q F & =\text { European Service Module Qualification Facility } \\ F C A & =\text { Fluid Control Assembly } \\ G F E & =\text { Government Furnished Equipment } \\ G N C & =\text { Guidance Navigation \& Control } \\ G S E & =\text { Ground Support Equipment } \\ H D R M & =\text { Hold Down and Release Mechanisms } \\ I C P S & =\text { Interim Cryogenic Propulsion Stage } \\ I S S & =\text { International Space Station } \\ I T L & =\text { Integrated Test Laboratory } \\ L A S & =\text { Launch Abort System } \\ L E O & =\text { Low Earth Orbit } \\ L O I & =\text { Lunar Orbit Insertion } \\ M D P S & =\text { Micrometeoroid/Debris Protection Shield } \\ M L I & =\text { Multi-layer Insulation } \\ M M H & =\text { Mono-methyl Hydrazine } \\ M M O D & =\text { Micrometeoroid and Orbital Debris } \\ M O N & =\text { Mixtures of Nitrogen } \\ M T L I & =\text { Multi-Trans Lunar Injection } \\ N A S A & =\text { National Aeronautics and Space Administration } \\ N R H O & =\text { Near-Rectilinear Halo Orbit } \\ O D N & =\text { Orion Data Network } \\ O M S-E & =\text { Orbiter Maneuvering System-Engine } \\ P C A & =\text { Pressure Control Assembly } \\ P Q M & =\text { Propulsion Qualification Model } \\ P R U & =\text { Pressure Regulation Unit } \\ R C S & =\text { Reaction Control System } \\ S A & =\text { Spacecraft Adapter } \\ S A D A & =\text { Solar Array Drive Assembly } \\ & \end{array}$




$\begin{array}{ll}\text { SADE } & =\text { Solar Array Drive Electronics } \\ \text { SADM } & =\text { Solar Array Drive Mechanism } \\ \text { SAJ } & =\text { Spacecraft Adapter Jettisoned Fairings } \\ \text { SAW } & =\text { Solar Array Wing } \\ \text { SLS } & =\text { Space Launch System } \\ \text { STA } & =\text { Structural Test Article } \\ T A S-I & =\text { Thales Alenia Space-Italy } \\ T C S & =\text { Thermal Control System } \\ T E I & =\text { Trans-Earth Injection } \\ T L I & =\text { Trans-Lunar Injection } \\ T V C & =\text { Thrust Vector Control } \\ V M C & =\text { Vehicle Management Computer } \\ W D S & =\text { Water Delivery System }\end{array}$

\section{Acknowledgments}

The work performed was initiated and guided by the NASA - ESA Orion program management, namely Mark Kirasich from NASA and Nico Dettmann and Philippe Deloo from ESA.

\section{References}

${ }^{1}$ Wilde, D., Schubert, K., Grantier, J., Deloo, Ph., Price, L., Fenoglio, F. and Chavy, S. "Building Transatlantic Partnerships in Space Exploration - The MPCV-SM Study,” GLEX-2012.15.1.10x12509 - Global Space Exploration Conference - 22-24 May 2012 - L'Enfant Plaza Hotel, Washington, DC, USA, URL:

http://ntrs.nasa.gov/archive/nasa/casi.ntrs.nasa.gov/20120012885_2012012562.pdf

${ }^{2}$ Berthe, Ph., Schubert, K., Grantier, J., Pietsch, K., Angelillo, Ph. and Price, L. “The Multi-purpose Crew Vehicle European Service Module: a European Contribution to Human Exploration,” AIAA 2013-5477 - AIAA SPACE 2013 Conference and Exposition, - 10-12 September 2013 - San Diego Convention Center, San Diego, CA, USA, URL:

http://ntrs.nasa.gov/archive/nasa/casi.ntrs.nasa.gov/20140010527.pdf 